\title{
EL PROBLEMA DE LAS VARIANTES FRASEOLÓGICAS DESDE LA PERSPECTIVA DE LA LINGÜÍSTICA DE VARIEDADES*
}

\author{
THE PROBLEM OF PHRASEOLOGICAL VARIANTS FROM A \\ VARIATIONAL LINGUISTICS BASED PERSPECTIVE
}

\section{CARSTEN SINNER}

Lingüística y Translación. Lenguas iberorrománicas. IALT, Universität Leipzig. sinner@uni-leipzig.de

\section{ENCARNACIÓN TABARES PLASENCIA}

Lingüística y Translación. Lenguas iberorrománicas. IALT, Universität Leipzig. tabares@uni-leipzig.de

\section{RESUMEN}

Los trabajos sobre fraseología aún no han podido dar con una respuesta satisfactoria a la pregunta de cómo establecer una diferenciación nítida entre lo que suele llamarse, en esta área, variantes, variaciones y modificaciones de las unidades fraseológicas. Este mismo problema tiene su paralelo en la lingüística de variedades. Esta rama de la lingüística persigue, entre otros objetivos, la distinción y clasificación de variedades y variantes de una lengua. Una de las cuestiones clásicas de la lingüística de variedades tiene que ver, precisamente, con la dificultad de trazar una neta separación entre diferentes lectos, idiolecto, por un lado, y sociolecto y funciolecto, por el otro. Nuestra contribución indaga en este paralelismo, profundizando en los solapamientos de las dos áreas de estudio y en las dimensiones teórica y terminológica del problema. Se realizará un análisis crítico de los diferentes enfoques teórico-metodológicos que se han presentado hasta ahora en ambos campos y se ofrecerá una nueva propuesta que prestará especial atención a la posibilidad de unir los ámbitos de la fraseología y de la lingüística de variedades para obtener una solución al difícil problema de las variantes fraseológicas.

Palabras clave: Unidades fraseológicas, variantes, criterios de diferenciación, lingüística de variedades.

* Este trabajo se ha desarrollado en el marco del proyecto FFI2014-58260-P, financiado por la Secretaría de Estado de Investigación, Desarrollo e Innovación del Ministerio de Economía y Competitividad de España (Proyectos I+D - Programa Estatal de Fomento de la Investigación Científica y Técnica de Excelencia. Subprograma estatal de generación de conocimiento). 


\begin{abstract}
Publications on phraseology have not yet given a satisfactory answer regarding the question of how to establish a clear differentiation between what in this area of research is generally called variants, variations and modifications of the so called phraseological units. This issue has certain parallels in variational linguistics (in the sense of the study of varieties of languages). This branch of linguistics aims, among other things, to distinguish and classify varieties of languages and linguistic variants. One of the classical issues dealt with in variational linguistics is related with the difficulty of tracing the separation line between different lects, that is, idiolects on the on hand, and sociolects (diastratical varieties) and functiolects (diaphasic varieties), on the other. This contribution deals with this parallelism, analyzing the overlapping of the two branches of linguistics and the related theoretical and terminological dimensions. In order to find a solution to the difficulties posed by the phraseological variation, we will carry out a critical analysis of the different models and theoretical and methodological approaches that were proposed in both fields of study in order to formulate our own proposal which takes into account the fundaments and the necessities of both fields of research.
\end{abstract}

Keywords: Phraseological units, variants, criteria of differentiation, variational linguistics.

Recibido: 23.03.2016. Aceptado: 10.08.2016.

\title{
1. INTRODUCCIÓN
}

\begin{abstract}
ún no se ha llegado a una solución satisfactoria para el problema de cómo establecer una clara distinción entre lo que en los trabajos sobre fraseología se ha denominado variantes, variaciones y modificaciones de las unidades fraseológicas (en adelante UF). Esta misma cuestión también se encuentra en la lingüística de variedades que aspira, precisamente, a diferenciar y categorizar variantes y variedades. Uno de los aspectos más polémicos de esta subdisciplina lingüística es el establecimiento de una frontera nítida entre diferentes lectos, esto es, entre idiolecto, por un lado, y sociolecto y funciolecto, por el otro.

A continuación se tratará este paralelismo con más profundidad, acercándose a las dos áreas de estudio, y a las dimensiones teórica y terminológica del problema desde una perspectiva crítica para así llegar a formular una nueva propuesta.
\end{abstract}

\section{LA LINGÜÍSTICA DE VARIEDADES Y SUS CONCEPTOS CENTRALES}

Antes de centrarse en esos paralelos, es necesario distinguir entre lingüistica de variedades y lingüistica variacional en el sentido laboviano. Esta última se ha venido 
entendiendo como el estudio sociolingüístico de variables lingüísticas y su concurrencia con otras variables lingüísticas o su correlación con variables extralingüísticas; por su parte, la lingüistica de variedades atiende a los siguientes objetivos:

(I) La descripción de las variedades y más concretamente:

○ de las variedades contenidas en el saber lingüístico de los hablantes o existentes en un espacio variacional ${ }^{1}$;

o de las relaciones entre estas variedades;

- de las relaciones entre las variedades de un espacio variacional con las variedades de otro espacio variacional; aquí entrarían en juego los contactos entre variedades de diferentes lenguas históricas;

o de la correlación de estas variedades con determinados factores extralingüísticos; la descripción de las variantes que comprenden una determinada variedad, y su análisis con respecto de las variables extralingüísticas con las que están relacionadas. Esta segunda orientación de la lingüística de variedades está estrechamente ligada con la siguiente área de estudio.

(II) El estudio de los orígenes de determinadas variedades, teniendo en cuenta su formación, tradición y evolución, es decir, también la deducción o atribución causal a determinados factores (generalmente extralingüísticos), como, por ejemplo, la formación de límites entre variedades debido a acontecimientos históricos, falta de vías de comunicación motivada por factores geográficos (pantanos, montañas, etc.) o por el establecimiento de fronteras político-administrativas (como los límites de una diócesis, etc.); con esta perspectiva está estrechamente relacionado el estudio del cambio lingüístico y sus causas.

(III) El estudio de la valoración y el estatus de las variedades: los hablantes y grupos de hablantes evalúan y categorizan a sus interlocutores o grupos de hablantes sobre la base de las variedades lingüísticas empleadas por éstos, ya que éstas nunca son vistas de forma neutral; por lo demás, las variedades pueden diferenciarse, por ejemplo, según su estatus explícito o implícito (que a su vez tiene que ver con el prestigio), por ejemplo, su reconocimiento como lengua oficial, lengua escolar, los dominios de uso, etc.

\footnotetext{
${ }^{1}$ Para Dittmar (1997: 175), una lengua es una suma de variedades (en el sentido de distintos sistemas de uso lingüístico) cuyas características se hallan fijadas en un espacio pluridimensional, como, por ejemplo, una interfaz de coordenadas histórica, geográfica, social y situacional. La descripción de un espacio variacional, por ende, está determinada esencialmente por la observación del comportamiento y patrones lingüísticos de los hablantes. También se ha hablado de arquitectura de la lengua; así, según Coseriu (1988), la lengua común se caracteriza por ser una estructura marcada por el entrelazamiento de las diferentes variedades que la conforman, esto es, sería una estructura arquitectónica de variedades.
} 
Por todo lo anterior, y a modo de corolario, cabría distinguir, en principio, entre (i) el estudio de los fenómenos característicos que pueden esperarse en un determinado grupo social o en una determinada situación y la (cor)relación de su uso con factores extralingüísticos, y (ii) la especificación y diferenciación de determinados sistemas a partir de una descripción de los fenómenos lingüísticos documentados en estos sistemas y de la determinación de su estatus. Queda patente que dicha descripción lingüística de las variedades necesariamente comprende (pero no se limita a) la observación de las variantes lingüísticas. Éstas, a su vez, pueden estar (parcial o completamente) relacionadas con variables extralingüísticas. Además, se ve claramente que, al preguntarse por los dominios funcionales de las variedades, hay que preguntarse igualmente por aspectos sociales, políticos, ideológicos, etc., es decir, que los aspectos sociolingüísticos pueden jugar un papel muy importante en la lingüística de variedades (cf. Sinner, 2014 para más detalles sobre estas cuestiones terminológicas).

En este punto es absolutamente necesario distinguir entre los conceptos de variación, variante, variedad y variable desde la perspectiva de la lingüística de variedades. La variación es considerada actualmente como la capacidad de las lenguas naturales de producir distintas realizaciones concretas en el habla. Variación significa, por tanto, que el mismo significado o el mismo contenido (Iturrioz y Skopeteas, 2000, lo llaman invariantes) pueda expresarse de diferentes maneras, usándose, para ello, realizaciones distintas, esto es, variantes. Variante se usa para la unidad lingüística concreta, individual, variedad para el sistema. Las variables lingüísticas, a su vez, tal y como se entiende en el caso de las variables matemáticas $x, y$, etc., pueden adquirir diferentes valores; en lingüística, estos valores serían las variantes lingüísticas. Esto puede ilustrarse con el ejemplo de la variable PRUNUS PERSICA, con las variantes melocotón (habitual en la España peninsular, Baleares, Canarias y algunas partes de Hispanoamérica) y durazno (usado en países como Chile, Argentina, Uruguay, México y Perú) (cf. el ejemplo de Ammon, 1995: 6165 para la lengua alemana).

Sin embargo, suele indicarse que en la lingüística no hay consenso acerca de lo que se supone que es exactamente una variedad y cómo se puede delimitar de otras variedades (cf. Nabrings, 1981, Steger, 1988, Dittmar, 1997, Baßler y Spiekermann, 2001, Löffler, 2005 y Sinner, 2014 acerca de este aspecto); dicho disenso se muestra particularmente en la lingüística anglosajona donde el debate en torno a la distinción entre variety y language, variety y dialect, variety y style, etc. -estrechamente ligados con una interpretación muy amplia de dialect- es muy frecuente. Berruto (2004: 189) considera problemática una definición estricta del término variedad, dado que ha de partirse del hecho de que una variedad lingüística se caracteriza porque ciertas realizaciones del sistema de la lengua coocurren de forma previsible con determinados rasgos sociales y funcionales. Según este autor, podría hablarse de una variedad lingüística cuando un conjunto de valores determinados 
(es decir, de realizaciones de formas que varían en la lengua en cuestión) aparecen junto a una determinada serie de propiedades que caracterizan al hablante o a una situación de uso (Berruto 2004: 189); retomando el ejemplo de la variable PrunUs PERSICA, habría que pensar en otras formas coocurrentes que permitirían la determinación de la variedad en cuestión, como, por ejemplo, su coocurrencia con el uso de ustedes o vosotros, de tú y vos, desde el punto de vista gramatical, del seseo, en lo fonético, de la preferencia de ciertas formas verbales (tomara vs. tomase, por ejemplo), etc.

No está claro qué cantidad y qué tipos de rasgos lingüísticos son necesarios para poder hablar de una variedad propia: ¿es suficiente que haya una sola variable lingüística con variantes diferentes? En efecto, se trata de una cuestión ya clásica que también ha marcado la historia de la dialectología. Ammon (1995: 64), entre otros, aboga por que se considere suficiente una sola variable para la diferenciación de variedades, si en la selección de las variantes de las variables lingüísticas se cumple, al menos, una de las dos condiciones siguientes: (i) disponer, como mínimo, de una variante específica, individual, o (ii) disponer, al menos, de una combinación específica de variantes.

Incluso suponiendo que una sola variable con diferentes variantes ya sea suficiente para distinguir dos variedades, se mantiene la cuestión de si, entonces, estas variantes tienen que ser usadas por todos los hablantes y realizadas de la misma forma en todas las ocasiones. Para ilustrar el problema de dilucidar el tipo y número de rasgos lingüísticos necesarios para establecer la distinción entre dos o más variedades, baste el ejemplo de una variable fónica con dos variantes en el árabe damasceno. En esta variedad del árabe existen dos variantes para el fonema /q/ (es decir, una variable (q) de la pronunciación): por un lado, el oclusivo uvular sordo [q], empleado en el estándar hablado, y un sonido oclusivo glotal sordo propio del habla coloquial [?]. Según un estudio de Daher (1998), es más probable que los varones usen [q] que las mujeres, mientras que estas últimas serían más propensas a realizar [?]. Esto se produciría de esta manera como consecuencia del hecho de que dichas variantes estén asociadas a determinados valores aceptados y defendidos en medida distinta entre hombres y mujeres. Además, se ha constatado una correlación entre el nivel cultural y el uso de una u otra variante, y así, es más probable el uso de [q] en sujetos con mayor formación. Cuando en este contexto se habla de probabilidad o propensión, se hace alusión a que, independientemente de la capa social, no todos aquellos que usan la variante [q] son hombres y que no sólo las mujeres emplean [?]. Sin embargo, desde un punto de vista puramente estadístico, es mayor la probabilidad de que las mujeres usen una variante y los hombres otra. Con ello, queda claro que, cuantitativamente, las variantes de la variable (q) se seleccionan dependiendo del sexo, es decir, que la variable ha de considerarse como diferenciadora del sexo, pero que no sirve como rasgo distintivo de dos variedades del árabe damasceno de forma unívoca. Aunque esta variante 
por sí sola no serviría para establecer la existencia de sociolectos, lo cierto es que junto a otras variantes (que posiblemente tampoco sean atribuibles únicamente a uno de los sexos) quizá sí lo permitiría.

Además, el término de la variedad se emplea tanto para subsistemas dependientes de una lengua (algo que en muchos contextos suele llamarse dialecto) como para referirse a sistemas lingüísticos completos y autónomos. En este sentido, habría que cuestionarse si no debería diferenciarse entre variedades diatópicas como variedades "completas" y las demás variedades (que no conforman variedades completas) (cf. también Dufter y Stark, 2003, respecto de este problema). De hecho, las variedades diatópicas ya se tratan de forma distinta a las demás variedades, si bien no siempre se dice de forma explícita. Otras variedades, como los sociolectos, estilos, registros, etc., se encuentran siempre subordinadas a las variedades diatópicas como sistemas integrales que pueden, a su vez, subdividirse en variedades diastráticas y diafásicas, que sólo constituirían "cortes" o "extractos" de las variedades diatópicas. Lo mismo cabe decir de la variedad que, según los diferentes modelos, se llama diamedial o diamésica (en referencia a los niveles escrito y hablado de la lengua), pero no del nivel diacrónico. Por esta razón algunos autores prefieren hablar de variedades secundarias cuando sólo en sentido más amplio se trata de un conjunto de rasgos coocurrentes con relevancia sociolingüística, mientras que otros autores rechazan la posibilidad de comprender estilos o registros como variedades y la excluyen de una definición más estricta de variedad (Androutsopoulos, 1998: 591; cf. Auer, 1989).

La dimensión diacrónica hay que tratarla aparte, ya que no puede partirse de una sola variedad diacrónica, sino de una dimensión que contiene todas las variedades de un diasistema (en el sentido de sistema de variedades) en un determinado momento en el tiempo y, como se vio, también merece un trato diferenciado el nivel medial (cf. para estas cuestiones, Sinner, 2014). A continuación, se verá detenidamente.

En la lingüística de variedades, según el modelo que se siga, se diferencian espacios variacionales que comprenden tres, cuatro o más variedades. Así pues, mientras que hay unanimidad respecto de la existencia de las variedades diatópicas, diastráticas y diafásicas (siendo las dos últimas como subordinadas a la primera), no ocurre lo mismo en cuanto a la existencia e integración de variedades basadas en otros ejes considerados más o menos esenciales en el estudio de las variedades. Serían los casos del eje histórico (con supuestas variedades llamadas, por los diferentes autores, históricas, diacrónicas, de tiempo, etc.) y del eje medial (escrito, oral y, olvidado por la mayoría de los autores, por señas) (con la propuesta de variedades llamadas mediales, mediolectos, mesolectos, etc.). Algunos autores insisten en la equiparación de variedades diacrónicas y variedades mediales con las tres variedades "clásicas" diatópicas, diastráticas y diafásicas, otros rechazan la posibilidad de variedades diacrónicas alegando que el eje temporal engloba las 
otras variedades (dado que habría variedades diatópicas, diastráticas y diafásicas en cada momento histórico, pero no una variedad diacrónica en sí). Por el contrario, otros rechazan la posibilidad de la existencia de variedades diamediales propias por considerar el medio como mero canal por el que llegan las variedades y que determinan su realización. Si bien diverge el número o el "catálogo" de las variedades, los autores coinciden, por lo general, en atribuirle un papel especial a la diatopía, que, jerárquicamente, suele posicionarse por encima de la diastratía y la diafasía. Además, al menos en la lingüística de tradición alemana y románica, suelen seguirse los postulados de Coseriu (1980), quien establece que las variedades diatópicas pueden funcionar diastrática y diafásicamente, es decir, que los dialectos pueden servir como niveles de lengua -sociolectos, variedades diastráticas-y los niveles de lengua, como estilos (como llama Coseriu a las variedades diafásicas).

El hecho de que en una sociedad el uso de una determinada variedad diatópica pueda ser equiparado a una determinada procedencia social puede conllevar el funcionamiento del dialecto en cuestión como sociolecto y que los hablantes también empiecen a emplearlo con dependencia de la situación, es decir, como variedad diafásica. Viendo cómo se solapan o entrelazan las variedades diatópicas, diastráticas y diafásicas, se entiende la razón por la que los dialectólogos muy tempranamente ya se interesaron por la dimensión social del uso de dialectos y por la que algunos autores ven los dialectos como unidad diatópica y diastrática (cf. Hutterer, 1984) o por qué la diferenciación de diastratía y diafasía se considere como una cuestión compleja. Hay que tener en cuenta, también, que la mayor parte de las publicaciones existentes se basan en modelos simplificados o idealizados, en los que se dejan de lado excepciones o casos extremos para evitar confusiones y evitar que los modelos resulten demasiado complicados. Debido a ello, suele partirse de una diferenciación clara y nítida de diatopía, diastratía y diafasía, muchas veces recordando sólo de paso que esta diferenciación habría que imaginarla como un continuum (cf. Sinner, 2014: 125-126).

Es particularmente difícil trazar una neta separación entre los diferentes "lectos", y especialmente entre los diferentes niveles, variables sociales, etc. con los que suele trabajarse. Así, queda por resolver cómo diferenciar entre idiolecto, por un lado, y sociolecto, por el otro (lo mismo cabe decir para la diferenciación de sociolecto y funciolecto). Este aspecto, sin embargo, es crucial para clasificar, desde la perspectiva de la lingüística de variedades, la diferenciación de lo que viene a llamarse variantes, variaciones o modificaciones desde la perspectiva de la fraseología.

$\mathrm{Al}$ observar el debate sobre la manera de cómo entender las variedades se constata que algunos autores sostienen que sólo puede partirse de la existencia de una variedad si los hablantes efectivamente la perciben como tal. Se ha debatido una y otra vez si esta percepción presupone la autopercepción o tan sólo la percepción por otros hablantes. Según Steinig (1976: 14 y ss.) la diferenciación de un sociolecto no requiere que los propios hablantes se cuenten a sí mismos entre las 
personas que formarían el respectivo grupo social, es decir, no haría falta que los mismos hablantes tuvieran conciencia de la existencia del sociolecto. Lo que sí es decisivo según este autor es que los hablantes de otras variedades los incluyan en el grupo social en cuestión. La actitud hacia los sociolectos se establece mediante la valoración de las realizaciones lingüísticas de otras personas, y esto se haría siempre con referencia a la variedad propia. Mientras que la diferenciación de variedades diatópicas es el resultado de la percepción de una variedad como "diferente" (de la propia y de las que uno ya conoce), en el caso de los sociolectos, la evaluación se hace a través de una valoración negativa o positiva. Si bien esta posición limita el alcance del sociolecto a las características lingüísticas que conciernen a la imagen y el prestigio del grupo social, esta definición ha recibido reseñas muy positivas en la lingüística (cf. Dittmar, 1997: 192 y Löffler 2005: 116).

La cuestión de la perspectiva externa está estrechamente ligada a la definición de grupo, porque la percepción como grupo puede darse desde una óptica externa o interna. De la misma manera en la que, a través del empleo discursivo de determinados medios lingüísticos, las personas construyen su propia identidad (tal como son empleados estos medios lingüísticos para alcanzar una determinada posición social como miembro de un determinado grupo social, por ejemplo; cf. Bauman, 2000), también la lengua de los demás es evaluada respecto de la conformidad con los patrones lingüísticos constitutivos o característicos de un grupo. El uso de la lengua y de estrategias discursivas puede, por tanto, ser parte del proceso de definición de grupos, de la formación de solidaridad de grupo, así como de la exclusión de un individuo de un grupo. Como señala Kremnitz (1995: 37) las comunidades de comunicación suelen ser bastante estables y, por regla general, tienen un impacto bastante grande sobre la constitución de grupos. Hay excepciones a esta regla, y la lengua no necesariamente tiene que jugar un papel importante para la formación de un grupo. No obstante, el uso de la lengua y, especialmente, el empleo simbólico de la lengua o de determinados fenómenos lingüísticos suelen entenderse como punto de partida muy importante para la determinación de la pertenencia a un determinado grupo. El uso simbólico de la lengua, ya sea el empleo de una determinada lengua en determinados contextos, ya sea el uso de determinados medios lingüísticos de una lengua, es crucial para la demostración de la propia pertenencia grupal (es decir, la inclusión grupal) y de la exclusión grupal de otros (marcas endogrupales y exogrupales); es decir, el empleo simbólico puede tener función emblemática y expresar pertenencia a un grupo social o expresar identidad social (Guy, 1988: 37 y Sinner, 2002).

Para Möhn (1998: 169), son característicos de un grupo los objetivos específicos del grupo, un sistema normativo (en el sentido de estándares sociales y comunicativos) bien desarrollado y una sensación grupal, del "nosotros" más que del "yo" que resulta de estos aspectos. Eso deja patente que la cuestión de la perspectiva si bien es importante, en ciertos contextos necesita ponerse en relación 
con la cuestión de la perspectiva interna. Desde la perspectiva externa, la lengua de otra persona puede ser identificada posiblemente como "no correspondiente a la propia variedad", "no correspondiente a la lengua del propio grupo", etc. Esto no significa que al mismo tiempo también sea posible identificar la variedad de la otra persona o atribuirla a un determinado grupo en concreto. En particular, sin conocimientos sobre variedades posiblemente ni siquiera sea posible diferenciar entre idiolecto y sociolecto como variedad de un grupo, es decir, distinguir si determinadas variantes lingüísticas (es decir, determinadas formas lingüísticas) o una combinación de variantes pueden explicarse como idiolecto o si han de explicarse con la pertenencia de una persona a un determinado grupo social. Brumme, en un estudio sobre el problema de diferenciar entre interferencias de otras lenguas y variabilidad intrínseca, ya da cuenta de este problema en el ámbito de la fraseología, al constatar que "el uso de las frases hechas se reparte de manera diferente por los países hispanohablantes, de modo que a veces se recupera en otra parte del mundo una que creíamos más frecuente en Cataluña. Además, resulta que el repertorio de las expresiones fijas es de por sí inestable, creándose muchas nuevas en cada generación y cayendo otras en desuso, a lo cual se añade el problema de la gran variación que experimenta el castellano en general" (Brumme 2008: 314).

El novelista White (2010: 168) recuerda una conversación con Peggy Guggenheim, coleccionista de arte de Nueva York, a la que había preguntado dónde había adquirido su extraño acento con vocales estridentes y una monótona entonación que contrastaba tanto con un vocabulario anticuado de adolescente que empleaba cuando estaba nerviosa:

In reply to my impertinent question she explained, "I went to a girls' school, the Jacoby school, on West Seventy-second Street, which was for rich Jewish girls. We weren't admitted to any gentile private schools and there weren't very many of us. But we were very close and we invented this way of talking and so we all spoke this way".

Peggy Guggenheim era consciente de la particularidad de su manera de hablar y de su pertenencia a un grupo -muy reducido- de amigas de colegio que compartían con ella estas características lingüísticas. Para extraños, que como Edmund White desconocían la existencia de este grupo y de esta explicación, su manera de hablar se presentaba como un idiolecto. Por lo tanto, resulta problemática la cuestión de quién es percibido como individuo y quién como parte de un grupo. La variedad de Guggenheim era percibida por otros como idiolecto -además uno visto como bastante excéntrico- porque ella "aparecía" como individuo y "su" grupo social, el grupo de personas ligadas entre ellas por el uso de esta variedad, era tan pequeño que sólo Guggenheim y sus amigas eran conscientes de que poseían una variedad grupal -es decir, un sociolecto (cf. el término alemán algo más 
preciso Gruppensprache 'lengua de grupo')-, mientras que cada una de las mujeres que formaban parte de este grupo era identificada por los demás como hablantes con idiolecto excéntrico. Esto relativiza la perspectiva externa como criterio para la diferenciación de grupos.

Es sintomático que Gumperz (1972), en uno de los textos fundamentales sobre etnografia de la comunicación, ni siquiera se detenga con una definición de group o a tratar el problema de la determinación del tamaño de un grupo. Así, cuando habla de small group se refiere aparentemente tanto a los habitantes de una aldea entera como a un grupo de adolescentes negros entrevistados en el marco de un estudio, o a una familia ("a family group") o, posiblemente, también a un matrimonio cuyas conversaciones con otros turistas se grabaron durante un viaje para ser estudiados después. Kubczak (1987) se plantea el número de personas que debe componer un grupo para poder referirse a este como grupo social. Además, se cuestiona si la variedad referencial tiene que ser un sistema lingüístico completo con capacidad suficiente para denominar todo tipo de realidades o si, más bien, sería suficiente que este grupo hiciera uso de un número más o menos grande de rasgos lingüísticos específicos que, por lo tanto, puedan considerarse como típicos de un determinado grupo. Lo ilustra con un grupo de jinetes como hablantes de una Reitersprache 'variedad de jinetes, variedad ecuestre' en el sentido de enunciados caracterizados por un gran número de terminología ecuestre. Kubczak cree que un subsistema o una variedad sólo pueden contar como sociolecto si el grupo de hablantes en cuestión es idéntico a una o varias capas sociales determinadas sociológicamente (Kubczak 1987: 269, cf. para más detalles, Kubczak, 1979), algo que, sin embargo, tampoco soluciona el problema del tamaño del grupo.

Se supone que las variedades idiolectales siempre contienen rasgos de otras dimensiones variacionales, como, por ejemplo, ciertos rasgos geográficos, sociales, cronolectales, etc. Puesto que, de esta forma, las características idiolectales siempre aparecen juntamente con fenómenos que personas ajenas pueden atribuir a variedades concretas, los idiolectalismos fácilmente pasan desapercibidos. A este respecto, parece esencial la opinión de Oksaar (2000) que declara que cualquier análisis realizado en el marco de un estudio orientado a la variación lingüística necesariamente tiene que englobar también un análisis del idiolecto, ya que toda variedad siempre está caracterizada por el idiolecto del emisor. Para la autora (cf. Oksaar, 1987, 2000), idiolecto es el acervo lingüístico y uso individuales de la lengua, es decir, la realización individual de las soluciones que ofrece el sistema. Lengua y variedades, sin embargo, sólo aparecen a través de la realización individual del sistema y son, por ello, punto de partida esencial para la determinación de comportamientos colectivos. Además, para la autora los idiolectos tienen un peso especial para la recepción de enunciados lingüísticos. Sin embargo, aún puede considerarse actual la queja de Dittmar (1997: 182-183) -con el que concluye su trabajo sobre posibles enfoques para estudiar los idiolectos- de que aún no se han 
analizado en cuanto a este aspecto.

En la llamada "tercera ola" de los estudios de la variación sociolingüística (cf. Eckert, 2012), se supone que los hablantes no son "portadores" de variedades estables y consolidadas, sino que su actuación se ubicaría en un nivel estilístico. Esta idea llevó a una avalancha de investigaciones idiolectales, esperando o creyendo, de esta forma, poder determinar los motivos de la variación estilística. De hecho, muchos de estos análisis presentados como estudios dialectales se limitan a la descripción de las realizaciones lingüísticas de una sola persona en diferentes (muchas veces sólo dos) contextos o momentos, como ilustra el estudio de caso realizado por Cutler (1999). Ahora bien, cabe señalar que este tipo de trabajos precisamente no permite examinar la posible gama de variación estilística que es posible en el seno de una variedad y tampoco posibilita la diferenciación de los rasgos meramente idiolectales. Sólo la comparación de realizaciones idiolectales sobre la base de un conjunto de datos cuantitativamente significativo permitiría la distinción entre variación individual y variación colectiva.

La demanda de Dittmar de una idiolectología comparativa para la descripción de registros individuales (cf. Fischer, 1958) y las afirmaciones sobre la acomodación idiolectal al entorno lingüístico (Giles y Powesland, 1975: 172) se quedan cortos: es especialmente necesaria la determinación del posible margen de variación en el idiolecto de un individuo para determinar el margen de variación posible en las variedades superiores, en la jerarquía de variedades supraordenadas. En un estudio sobre la modalidad lingüística de franceses en edad avanzada, Gerstenberg (2011: 109) constata divergencias estilísticas en los enunciados de sus informantes en conversaciones con diferentes entrevistadores, si bien aún faltan estudios empíricos más amplios sobre cómo repercuten en el cambio de registro los diferentes entrevistadores.

Cabe pensar que, por medio de una comparación de los cambios estilísticos mencionados, pueda determinarse el alcance de los cambios estilísticos posibles anclados en el repertorio de los hablantes de un determinado grupo social y cuáles de éstos representan divergencias idiolectales.

Lo mismo, obviamente, puede predicarse para la determinación de si una estructura parecida a alguna UF conocida es resultado de una creación ad hoc individual, resultado de un lapsus, falta de disponibilidad léxica, influencia de otra(s) lengua(s) en el caso de personas bilingües o plurilingües, etc., o si se trata de un elemento que se da en los miembros de un determinado (sub)grupo social como variante de la forma reconocida como estándar.

Hacen falta, no cabe duda de ello, estudios empíricos basados en corpus, ya sean escritos u orales, y lo más extensos posibles, dejando de lado las prácticas caducas de basarse en las entradas de obras lexicográficas que casi siempre carecen de procedencia temporal y geográfica exactas, frecuencias, etc., o de apoyarse en estudios obsoletos o datos no comparables entre sí. 
Seguidamente ofrecemos un panorama de los estudios hispánicos de la variación fraseólogica para mostrar la necesidad de replanteamiento de esta cuestión tan polémica.

\section{EL ESTUDIO DE LA VARIACIÓN EN EL ÁMBITO DE LA FRASEOLOGÍA HISPÁNICA}

Antes de hablar del tratamiento de la variación fraseológica se quiere precisar que en estas páginas se sigue una concepción ancha de la fraseología. La concepción estrecha, que se centraría en las locuciones como elementos que se hallan en una oración con una función sintáctica determinada (Fleischer, 1982: 72-73)2 , se considera demasiado reduccionista pues expulsa del paraíso fraseológico a las colocaciones ${ }^{3}$, proverbios, refranes y otro tipo de enunciados de carácter pragmático ${ }^{4}$. Desde nuestro punto de vista, un fraseologismo sería una unidad lingüística constituida, por regla general, por una combinación de dos o más palabras caracterizada por diversas propiedades. Las propiedades fundamentales que definirían las unidades fraseológicas en el ámbito de la lengua general ${ }^{5}$ serían la frecuencia de coaparición de sus componentes, la fijación ${ }^{6}$ y la idiomaticidad, que se concebirían como magnitudes graduales. Así lo expresaba Corpas Pastor (1996: 20) en su famosísima definición: "Unidades léxicas formadas por más de dos palabras gráficas en su límite

2 Dentro de la concepción estrecha, hay autores como García-Page (2008: 30), que, sin embargo, sí admiten la existencia de las locuciones oracionales.

${ }^{3}$ Como indica Salvador (2000: 25), es el carácter asociativo que particulariza a las colocaciones una regla general en las lenguas y no la excepción periférica; por eso consideramos que es necesario incluir dentro del fenómeno fraseológico a las colocaciones.

${ }^{4}$ En este sentido también hay que llamar la atención acerca de la ambigüedad terminológica y nocional en este campo, porque no todos los investigadores utilizan los mismos términos para los mismos fenómenos fraseológicos y no todos asumen como fraseológicos los mismos tipos de unidades. Así pues, el concepto de locución no es exactamente el mismo para Corpas Pastor (1996) que para Ruiz Gurillo (1997), como tampoco el de colocación para Corpas Pastor (1996) y para Benson (1985), por ejemplo (véase también a este respecto Montoro del Arco, 2006: 91). Asimismo, mientras que Corpas Pastor (1996) asume sin reservas a las colocaciones como elementos fraseológicos, Zuluaga (1998) no las contempla dentro de la fraseología y Ruiz Gurillo (1997) las sitúa en su periferia.

${ }^{5}$ Aludimos explícitamente a la lengua general porque consideramos que dentro de los textos especializados las unidades fraseológicas presentan ciertas características no atribuibles, o no atribuibles de la misma manera, a las unidades no especializadas. Así pues, la idiomaticidad debe ser entendida en estos casos como prototipicidad (cf. Tabares Plasencia, 2012: 321).

${ }^{6}$ La fijación también ha sido objeto central de estudio en la tradición fraseológica de lengua francesa. Concretamente, Gross (1997: 203) habla de esta propiedad como una cuestión central dentro de las lenguas e insiste en su carácter gradual. Asimismo (Gross, 2014: 44) destaca que es la sintaxis y no sólo la metáfora la causante de la fijación de las locuciones. Por su parte, Mejri (2005: 186) considera la fijación como una característica que admite grados, siendo que la fijación absoluta consistiría en el grado máximo de fosilización de una formación sintáctica. 
inferior, cuyo límite superior se sitúa en el nivel de la oración compuesta. Dichas unidades se caracterizan por su alta frecuencia de uso, y de coaparición de sus elementos integrantes; por su institucionalización, entendida en términos de fijación y especialización semántica; por su idiomaticidad y variación potenciales; así como por el grado en el cual se dan todos estos aspectos en los distintos tipos".

Creemos que esta definición sigue manteniendo su vigencia, a pesar de que algunas de las características de las unidades fraseológicas que menciona la autora no han dejado de ser controvertidas; por ejemplo, la idiomaticidad, que algunos autores han unido a la no composicionalidad del significado de la expresión fraseológica (cf. Mejri y Desporte, 2010). Otros autores han asociado la idiomaticidad con un grado de especialización semántica tal que derivaría en la opacidad de la expresión fraseológica, mientras que algunos otros, en esta misma línea, hablan de esta propiedad unida a un significado traslaticio. Montoro del Arco (2006: 48), por su parte, considera que es el producto, desde el punto de vista sincrónico, del proceso diacrónico de la lexicalización, y que puede llegar incluso a la gramaticalización. También es muy controvertida la cuestión de la fijación, relacionada, precisamente, de manera directa con la variabilidad de las unidades fraseológicas. Así, la "potencial variación” ya aparece en la definición de Corpas (1996, supra) y de Montoro del Arco (2004 y 2005), como veremos más abajo. Mogorrón Huerta (2010a), por su parte, considera que la fijación y la variación se hallan indefectiblemente unidas.

La variación fraseológica ha sido objeto de análisis desde hace bastante tiempo, con resultados no demasiados satisfactorios, sobre todo -creemos-, porque no se han definido claramente las categorías que se han empleado para hablar de este fenómeno frecuente en la fraseología. En el fondo, incidimos siempre en un problema terminológico, tanto en su vertiente denominativa como conceptual.

Corpas (1996: 27 y ss.) en su manual de referencia en el mundo hispánico trata el fenómeno de la variación partiendo de los presupuestos de Zuluaga (1980) y establece una distinción entre variantes y modificaciones. La autora define las variantes según las características que Zuluaga ofrecía en sentido estricto, es decir, éstas tienen que pertenecer a la misma lengua funcional y no presentar diferencias de significado. Además, deslinda las variantes de las simples variaciones por derivación (ser un culo/un culillo de mal asiento, p.e.) o transformación (v.gr. estallido de la guerra, nominalización de estallar la guerra). Tampoco considera variantes las UF que forman parte de series con significado opuesto (pasar la época de las vacas gordas(flacas), las variaciones diatópicas, las variaciones diafásicas ni las que contendrían casillas vacías (a miltu/su parecer..., p. e.).

García-Page (1996: 479), por su parte, presenta un concepto de variante propio, definiéndola como una construcción prefabricada que permite la sustitución de alguno de sus componentes léxicos sin que el significado de la construcción se vea alterado. En su conceptualización, se muestra como una característica central la fijación del significado y la restricción en el cambio léxico. Unos años después, 
García-Page (1999) hace suya la clasificación que divide entre variantes léxicas, morfológicas, gramaticales y gráficas, interesándose, sobre todo, por las alteraciones morfológicas. Más tarde (García-Page, 2008: 256-281) añade a su teoría de la variación fraseológica que ni las transformaciones gramaticales (nominalizaciones, pronominalizaciones y pasivización) ni las variaciones libres convencionalizadas constituyen variantes en sentido estricto porque su conmutación no se daría dentro de lo que el autor llama repertorio fraseológico del español, sino que son individuales y creativas, de carácter ocasional. Con repertorio fraseológico el autor no deja claro cuál es su referente. Nos imaginamos que se refiere a las unidades constatables en los diccionarios.

Por su parte, Koike (2001 y 2003) entiende por variantes fraseológicas aquellas combinaciones lingüísticas con el mismo significado casi idénticas en su estructura y componentes. Así pues, este autor considera que construcciones como hacer la pelota, hacer la rosca, hacer la barba son variantes (o sea, covariantes, formas que significan lo mismo -lo que nosotros llamaríamos variable-) por cambiar sólo el segundo elemento léxico, pero no lo sería chupar las medias, que tiene el mismo significado, pero difiere de las anteriores en ambas formas. Para el autor japonés, las variantes fraseológicas pueden ser producto de la variación morfológica, sintáctica o léxica. En cuanto a la variación morfológica, este destacaría los siguientes supuestos: a) variación por derivación (contar batallas/ batallitas); b) variación por cambio de número gramatical (criar a alguien entre algodón/algodones). Atribuye a la variación sintáctica el cambio de preposiciones y artículos, de orden de los elementos y su estructura sintáctica, entre otros: levantarse delcon el pie izquierdo (cambio de preposición); no dar sulel brazo a torcer (cambio de determinante); ser uña y carnelser carne y uña (cambio en el orden de los elementos de la construcción); hacer la vista gorda/hacerse de la vista gorda (cambio en la estructura sintáctica). La variación léxica, por su parte, consistiría en el empleo de una unidad léxica por otra. Aunque las variantes léxicas no obedecerían necesariamente a factores geográficos (diatópicos), para Koike sí que el factor geográfico podría considerarse entre las causas de la variación léxica. Uno de los ejemplos que da es ser uña y mugre (México) vs. ser uña y carne (España) y ser uña y diente (República Dominicana). También destaca Koike las UF homónimas, esto es, construcciones con idéntica forma, pero diferente significado, como sería el caso de, por ejemplo, ahuecar el ala que en España significa 'irse rápidamente de un sitio' mientras que en Guatemala y Honduras se supone que significa 'enamorar, seducir'.

Para Montoro del Arco (2004 y 2005), la variación y fijación en el fenómeno fraseológico son dos caras de la misma moneda. Para el autor, las variaciones ya sean variantes o variaciones en el sentido de Zuluaga- deben tener el mismo significado, ser libres (eso es, ser independientes del contexto) y ser muy similares en su estructura y en sus constituyentes. Montoro del Arco (2005: 138-144) distingue, dentro de las variantes, entre: (i) variantes internas (esto es, intrínseca- 
mente lingüísticas), agrupadas, a su vez, en léxicas, morfoléxicas y gramaticales, y (ii) variantes externas. Estas últimas pueden estar motivadas geográfica (variantes diatópicas), social (variantes diastráticas) o contextualmente (variantes diafásicas), amén de por evolución temporal (variantes diacrónicas). Asimismo, considera el fenómeno de lo que él mismo denomina variaciones estructurales, donde tendrían encaje (a) la variación léxico-cuantitativa o por extensión: incrementos que prácticamente no afectan al significado global. Aquí cabría mencionar: (aa) incrementos, sustracciones y complementaciones (bilar (muy) fino); (ab) variaciones gráficas (a bocajarrola boca de jarro); (ac) citas interrumpidas fijadas (cría cuervos...); y (b) las variaciones morfosintácticas como (ba) cambios de género y número (sano y salvo, sana y salva, sanos y salvos, sanas y salvas); (bb) cambios del orden de los elementos (qué sé yolyo qué sé) o (bc) nominalizaciones (estallido de la guerra) y, finalmente (bd), UF con casillas vacías (a mis/tus/sus anchas).

Por lo demás, la inmensa mayoría de los fraseólogos separan igualmente entre el fenómeno de la variación y de las modificaciones. Según Corpas Pastor (1996: 29), las variantes carecen de la intencionalidad del hablante, mientras que las modificaciones tienen que ver con la manipulación creativa e intencionada del mismo ${ }^{7}$. Alvarado Ortega (2008: 16-17), por su parte, considera con Corpas Pastor (1996) y Ruiz Gurillo (1997: 21) que el fenómeno de la modificación está estrechamente ligado a la idea de desautomatización, entendida como la manipulación en la forma o contenido de una UF para producir determinados efectos. Por el contrario, piensa que las variantes se dan en las UF cuando presentan un solo cambio léxico en su estructura, bien sea por adición o reducción, bien por sustitución, sin alterar su componente principal, su significado, en los contextos en los que puede aparecer. Además, se incluirían dentro de las variantes los cambios de registro y los cambios de código, siempre y cuando fueran comprendidos por el oyente como tales. Por último, Mena Martínez (2003), aparte de considerar la modificación y la variación, también incluye la desviación, como la reproducción errónea de una UF, dentro del fenómeno general que ella denomina variabilidad.

En la Tabla I, en la que se incluyen algunas de las propuestas que se han realizado en torno a la llamada variación fraseológica en el ámbito de la lengua española ${ }^{8}$, se puede ver panorámicamente el caos terminológico existente en torno a esta cuestión.

${ }^{7}$ En este caso se asocia la modificación con el fenómeno de la desautomatización, considerado, de manera generalizada, como un proceso de cambio de la unidad fraseológica de manera consciente y deliberada. Resulta interesante, por ello, la sugerente propuesta de Martí Sánchez (2014: 97-98) que habla de una desautomatización no intencional, que él denomina "periférica, espontánea y no ostensiva” y que sería una reacción a la automatización y a la desmotivación de las expresiones fraseológicas.

${ }^{8}$ Por supuesto, este fenómeno ha sido tratado desde un punto de vista teórico, y en relación a otras lenguas, por muchos autores. Por ejemplo, se han encargado del mismo con especial referencia para el alemán y el ruso Dobrovol'skij (1988), Barz $(1986,1992)$ y Burger (2000). 
Tabla I. Distintos modelos de variación fraseológica en el ámbito hispánico.

\begin{tabular}{|c|c|c|}
\hline Autor & Tipos & Características \\
\hline \multirow[t]{2}{*}{$\begin{array}{l}\text { Zuluaga } \\
(1980)\end{array}$} & Variante stricto sensu & $\begin{array}{l}\text { Debe darse dentro de una misma lengua funcio- } \\
\text { nal. } \\
\text { No se admiten diferencias de sentido. } \\
\text { Es libre, independiente de contextos. } \\
\text { Se da identidad parcial de su estructura y com- } \\
\text { ponentes. }\end{array}$ \\
\hline & Variación lato sensu & $\begin{array}{l}\text { Transformación de una UF que lleva aparejada } \\
\text { cambio de sentido. } \\
\text { Disparidad de estructura y componentes con } \\
\text { identidad semántica (sinonimia fraseológica) } \\
\text { Variantes diatópicas, diastráticas y diafásicas }\end{array}$ \\
\hline \multirow[t]{2}{*}{$\begin{array}{l}\text { Corpas Pastor } \\
(1996)\end{array}$} & Variante & $\begin{array}{l}\text { Las mismas características que las variantes stricto } \\
\text { sensu de Zuluaga (1980) }\end{array}$ \\
\hline & Modificación & $\begin{array}{l}\text { Tiene un carácter intencional por parte del ha- } \\
\text { blante. } \\
\text { Supone la manipulación creativa e intencionada } \\
\text { de una UF para generar determinados efectos. } \\
\text { Este tipo de manipulación se relaciona con la } \\
\text { desautomatización de la UF de base (en este } \\
\text { mismo sentido, entre otros, Ruiz Gurillo, 1997; } \\
\text { Burger, 2003; y Alvarado Ortega, 2008) }\end{array}$ \\
\hline \multirow[t]{2}{*}{$\begin{array}{l}\text { García-Page } \\
(1996,1999, \\
2008)\end{array}$} & Variante & $\begin{array}{l}\text { Construcción prefabricada que permite que } \\
\text { alguno de sus elementos léxicos sea sustituido sin } \\
\text { que su significado se vea alterado. } \\
\text { Modulación de diversa naturaleza en esa cons- } \\
\text { trucción prefabricada: fónica, gráfica, morfo- } \\
\text { lógica, gramatical, sintáctica, léxica, diatópica, } \\
\text { diastrática, diafásica y diacrónica. }\end{array}$ \\
\hline & Variación & $\begin{array}{l}\text { Las posibles alternativas léxicas (sinónimos). } \\
\text { Las expresiones fijas sinónimas. } \\
\text { Las fórmulas de relleno. } \\
\text { Los antónimos. } \\
\text { Las variaciones espontáneas e individuales. }\end{array}$ \\
\hline $\begin{array}{l}\text { Koike }(2001, \\
\text { 2003) }\end{array}$ & Variante & $\begin{array}{l}\text { Identidad parcial de dos o más unidades en su } \\
\text { estructura y sus componentes. } \\
\text { Se produce un cambio de estructura en las uni- } \\
\text { dades por motivos gramaticales, sintácticos o } \\
\text { léxicos. } \\
\text { Identidad semántica. }\end{array}$ \\
\hline
\end{tabular}

${ }^{9} \mathrm{El}$ autor no incluye estos tipos dentro de las variantes stricto sensu porque no serían formas, a su modo de ver, ni dentro de la misma lengua funcional en el sentido coseriano ni de la misma modalidad de lengua. 
Continuación Tabla I.

\begin{tabular}{|l|l|l|l|}
\hline $\begin{array}{l}\text { Mena Martí- } \\
\text { nez (2003) }\end{array}$ & Variabilidad & Desviación & $\begin{array}{l}\text { Forma incorrecta de la UF motivada por distin- } \\
\text { tas causas, como el nerviosismo, o la inmediatez } \\
\text { del discurso, etc. }\end{array}$ \\
\cline { 3 - 4 } & & Variante & $\begin{array}{l}\text { Unidad que es idéntica a otra en cuanto a su } \\
\text { significado y que comparte con ella algunos } \\
\text { elementos léxicos. }\end{array}$ \\
\cline { 3 - 4 } & Modificación & $\begin{array}{l}\text { Cambio consciente de la UF con determinados } \\
\text { efectos estilísticos (desautomatización). }\end{array}$ \\
\hline $\begin{array}{l}\text { Montoro del } \\
\text { 2005) }\end{array}$ & Variante interna & $\begin{array}{l}\text { Léxica. } \\
\text { Morfo-léxica. } \\
\text { Gramatical. }\end{array}$ \\
\cline { 2 - 3 } & Variante externa & $\begin{array}{l}\text { Variante diatópica. } \\
\text { Variantes diastráticas. } \\
\text { Variantes diafásicas. } \\
\text { Variantes diacrónicas. }\end{array}$ \\
\hline & Variación estructural & $\begin{array}{l}\text { Modificación léxico-cuantitativa o por extensión. } \\
\text { Variaciones morfosintácticas. }\end{array}$ \\
\hline
\end{tabular}

No se puede finalizar este apartado sin mencionar la propuesta, más actual, de Penadés Martínez (2014), que introduce los conceptos de variación marcada y no marcada en el ámbito de las locuciones ${ }^{10}$; y los trabajos de Mogorrón Huerta (2010b, 2010c, 2014a y 2014b), por lo que a la variación diatópica dentro del ámbito hispánico se refiere. El caos terminológico, por un lado, dificulta la labor de la fraseología y, por el otro, complica la integración de los resultados de los estudios fraseológicos en otros ámbitos de la lingüística, como, precisamente, la lingüística de variedades. Demos paso, entonces, al debate de estos problemas y una propuesta para solucionarlos.

\section{PROPUESTA Y DEBATE}

Para comenzar, se quiere simplificar la cuestión de la terminología en relación a la variación fraseológica. Se considera que la generación de todos estos términos

${ }^{10}$ Penadés Martínez (2014) retoma los conceptos generales de variación diacrónica, diatópica, diastrática y diafásica y no considera ni la antonimia ni la sinonimia como formas de variación (2014: 64-65); por su parte, emplea el calificativo no marcado para referirse al uso neutro de una variante, es decir, que esta pueda encontrarse indiferenciadamente en diversos contextos. Por el contrario, marcado indicará el empleo de una variante fraseológica en un determinado estado de lengua, en una determinada diatopía, "específica de hablantes caracterizados por alguna variable social o particular de alguna situación comunicativa o de modalidad de lengua" (2014: 68). Asimismo, "las que se están llamando aquí variantes marcadas corresponderían a las variantes condicionadas de la sociolingüística” (2014: 68 en nota). 
(variabilidad, variación, variante, modificación, desviación, etc.) que, muchas veces, aluden al mismo concepto, y de diferentes conceptos que se expresan con la misma forma denominativa no ayudan a clarificar el panorama en el estudio del "cambio" que se produce en las UF. No pocos fraseólogos defienden que la terminología ya se halla "establecida" y que, por tanto, no hace falta recurrir a nuevas reformulaciones; así se ha destacado en algunos foros científicos, entre ellos, en el V Coloquio Lucentino Fraseología, variaciones, diatopía y traducción que tuvo lugar en la Universidad de Alicante a finales de octubre de 2014. Muy al contrario, estamos convencidos, a la luz de todo lo expuesto en el apartado 3, de que no está justificado en absoluto hablar de una terminología establecida, ni mucho menos de una uniformidad terminológica.

Estemos ante un caso de deturpación o desviación fraseológica (como quiere Mena Martínez, 2003), ante uno de modificación consciente o en presencia de cambios fónicos, morfológicos, sintácticos o léxicos, lo cierto es que, en todos los supuestos, se trata de lo que en el apartado 2 de este trabajo se definió, desde el punto de vista de la lingüística de variedades, como variante. Variante se usa, como se indicó entonces, para la unidad lingüística concreta, individual; es decir, variantes son realizaciones distintas para representar una variable. Por tanto, en un primer momento, resulta indiferente qué es lo que ha motivado esta realización concreta; es decir, es irrelevante, para este primer nivel de clasificación, si se trata de un error individual, de una interferencia de otra lengua o de una unidad que sólo se emplea en ciertos grupos; el caso es que todos estos supuestos constituirían variantes de una variable.

Ahora bien, en la lingüística de variedades, como también se expuso, resultan precisamente palmarias la complejidad y, a veces, la imposibilidad de determinar el estatus de un elemento: por ejemplo, decidir si estamos ante una variante individual (que pueda responder a un error individual o ser un elemento implementado en un idiolecto) o ante una variante grupal, etc.

Además, cuando los fraseólogos emplean la terminología al uso, lo hacen muchas veces de manera apriorística, excluyendo que puedan existir otras lecturas, ya que, al decidirse por un término de un determinado modelo descriptivo, se adelantan a los estudios de caso que podrían llegar a otras conclusiones. Usar cualquiera de los términos que vayan más allá de variante implica el problema de poner una etiqueta preestablecida que descarta otras posibilidades. Estas "etiquetas" se sostienen generalmente sobre lo que dice "la norma" (entiéndase, la norma prescriptiva), y lo que se documenta en las obras lexicográficas, que suelen ser la fuente de donde extraen las UF con las que se "contrastan" las formas que se pretenden clasificar.

La cuestión a la que se hace referencia aquí, y de la que no se suele hablar en fraseología, es justamente la siguiente: ¿cuál es la forma “invariante” (en el sentido de variante primaria), y ¿cuál es la (o cuáles son las) que, por la razón que sea, 
debe(n) considerarse como variante(s) (secundaria(s)? Porque si lo cierto es que las UF "sufren cambios", hay que precisar: ¿cambios en relación con qué? ¿Y cómo se determina cuál es la UF canónica o de base sobre la que se operan cambios? ¿Y esto se deberá determinar atendiendo a las formas que se hallan registradas en las obras lexicográficas? ¿Y a partir de cuándo se crea una UF y se establece como forma canónica? En este punto, debemos señalar que la mayor parte de los estudios fraseológicos parten del texto escrito, de géneros textuales que suelen reproducir el estilo culto, i. e., lo escrito y lo culto se hallan sobrerrepresentados, mientras que no se atiende también, y como se debiera, a la oralidad y a registros de la lengua de proximidad. En particular, no se encuentra descrito en su justa medida lo que se considera diastráticamente bajo. En este sentido, decir que es incorrecta o desviada la realización de una determinada UF que se aleja de la forma considerada canónica es, cuando menos, una temeridad si no se efectúa un análisis empírico sobre la frecuencia de la(s) forma(s) en cuestión. Quizá la forma no canónica viene respaldada por un uso mayoritario en un grupo o una comunidad mayor. Por tanto, los conceptos de corrección o incorrección, de normativo (en el sentido de prescriptivo) y no normativo son siempre relativos. Por lo demás, incluso realizaciones producto de un lapsus linguae o debido al desconocimiento o a la supuesta falta de competencia fraseológica pueden establecerse y extenderse en su uso. Así, poco a poco pueden alcanzar el estatus de variante "del sistema", llegar a convertirse, incluso en norma en el sentido coseriano (o sea, lo que es usual para los hablantes, en el sentido de variante principal).

A continuación se presentan algunos ejemplos de casos que ilustran muy bien por qué es necesario, en un primer nivel clasificatorio, hablar sólo de variante, evitando calificadores a priori que correspondan sólo a una versión parcial del uso de las UF en el mundo hispánico.

Buen ejemplo de un lapsus que parece que se repite es el ejemplo que Mena Martínez (2003) atribuye a la periodista española Nieves Herrero: no es todo el oro el que reluce. Otro caso que ilustra un uso que se considera lapsus o error por falta de competencia fraseológica es el archifamoso estar en el candelabro (pronunciado por la modelo española Sofía Mazagatos al indicar, en una entrevista, que le gustaban los toreros que estaban en el candelabro ${ }^{11}$ ). El solo hecho de establecer una diferencia entre los dos casos, explicando que el último está motivado por deficiencias culturales, ya es buena muestra de la arbitrariedad y falta de criterio a la

${ }^{11}$ En torno a esta expresión, sobre todo en lo que respecta a la proximidad semántica entre candelero y candelabro, resultan interesantes las palabras de Gómez Capuz (2006): “También es fruto de una etimología popular la modificación de la locución verbal estar en el candelero 'estar de moda, estar en posición destacada' (Larousse, 2001: 76) por la expresión, extraña y casi catalogable como metáfora surrealista, estar en el candelabro, como hizo Sofía Mazagatos (aunque, curiosamente, como unidades léxicas individuales, candelero y candelabro pueden ser sinónimas en el sentido de 'soporte para una vela')". 
hora de clasificar formas reconocidas como versiones "divergentes" de una forma considerada normativa. Sería indicado realizar estudios sobre prejuicios lingüísticos relacionados con este uso. Que no es todo el oro el que reluce sea considerado lapsus y no resultado de falta de cultura se debe, en muchos casos, a quién haya reproducido desviadamente la UF (en nuestros ejemplos, una periodista considerada bien formada y una modelo vista como con grandes deficiencias culturales). El hecho de tener una formación universitaria no implica que no se pueda tener una competencia fraseológica limitada o deficiente, y, a contrario, el hecho de que se tenga escasa formación académica no implica que todos los lapsus sean por falta de competencia fraseológica. Sin duda alguna, estar en el candelabro, en España, además ya ha pasado a formar parte de un registro humorístico y, por tanto, en ciertos momentos es usado con intención, lo que lo convierte, sin duda alguna, en una variante, empleada conscientemente, de estar en el candelero. Durante las conversaciones mantenidas en el coloquio antes mencionado sobre Fraseología, variaciones, diatopia y traducción a finales de octubre de 2014, uno de los presentes, lingüista español, especializado en fraseología, se equivocó y pronunció, precisamente, estar en el candelabro cuando lo que quería era emplear la construcción canónica. Nadie de los presentes pensó en otra cosa que un lapsus linguae.

Es bien sabido que no pocas expresiones usadas hoy en día en el lenguaje, hace unas décadas, o hace unas generaciones, se consideraban errores no tolerables. Entonces, ¿por qué se va a suponer que en el ámbito de la fraseología ocurra otra cosa distinta? Ocurre así, por ejemplo, en el caso de analogías de género gramatical como manito (perfectamente aceptado actualmente como americanismo) en lugar de la forma manita que sería la esperable atendiendo las reglas de la formación de diminutivos, o de modisto (admitido en todo el mundo hispánico) en lugar de modista (que era la forma tradicional, al ser mayoritariamente mujeres las que ejercían esta profesión) o los usos graduados del descendiente castellano del comparativo latino mayor.

Además, la calificación de una forma como errónea tiene que partir del análisis de otra forma considerada normativa, estándar, normal, etc. Es algo que para muchos idiomas no puede ni siquiera hacerse antes de realizar una completa descripción de la lengua. Además, proceder así imposibilita el acercamiento, de forma diacrónica, a la fraseología. Haría falta determinar, sin dejar lugar a dudas, la posición de cada forma en el sistema para establecer cuál es la canónica y cuáles son las variantes. Se remite aquí al mencionado ejemplo de candelabro vs. candelero, otro buen ejemplo sería el caso de construcciones consideradas coloquiales o vulgares y no siempre registradas en los diccionarios, como echar(se) un polvo vs. echar(se) unos polvos, siendo que el Diccionario de la Real Academia Española (2014) sólo recoge echar un polvo (s.v. polvo).

Puede resultar particularmente espinosa la determinación del estatus de variantes cuando se trata de formas cuyo uso sólo se puede considerar como "normal" o 
"habitual" en ciertas variedades diatópicas. El desconocimiento de esa otra variedad fácilmente lleva a hablantes de otras variedades a pensar en errores lingüísticos. Tal como se recoge en Tabares Plasencia (2006, (2): 844), la construcción hacer confianza (en alguien) es una expresión que en el habla tradicional de La Gomera se utiliza más que los verbos confiar en o fiarse de y que se usa más que la construcción verbonominal más general tener confianza. La autora da el siguiente ejemplo que procede de las entrevistas grabadas por ella: "Nosotros, cuando principió a hablar, pensamos que era un hombre de muchas inteligencias y que valía. Pero, iqué va, cristiana!: no se podía hacer confianza en él. Antes de irse hizo unas cuantas. Ya la gente sabe quién es" ${ }^{\prime 2}$.

Esta estructura ha sido considerada por otros hablantes de las islas Canarias no familiarizados con la variedad gomera tradicional como errónea o, cuando menos, extraña. El estudio empírico de Tabares ${ }^{13}$, sin embargo, ha mostrado que se trata de un fraseologismo de uso normal y frecuente entre una comunidad hablante determinada de La Gomera.

La misma estructura, sin embargo, también se ha podido constatar en otros lugares y contextos. Así, uno de los autores del presente trabajo, hace unos ocho años escuchó la expresión hacer confianza en alguien en Barcelona a una niña de ocho años hablando de sus clases de natación y de la calidad de los profesores: "Hago

${ }^{12}$ Este ejemplo y los siguientes, extraídos de Tabares Plasencia (2006), divergen de la transcripción que la autora usa en su obra. Aquí se ofrece una transcripción ortográfica y no fonética para facilitar la lectura.

${ }^{13}$ Este trabajo de Tabares Plasencia constituye un estudio del léxico y fraseología del español tradicional de la isla de La Gomera (islas Canarias, España). El estudio de la fraseología constituyó la parte más novedosa de esta monografía, dado que para clasificar y analizar las unidades que se aislaron se hizo uso, por primera vez en el campo de la fraseología canaria, del modelo de Corpas Pastor (1996). Este estudio era lo suficientemente amplio para abarcar todos los fenómenos fraseológicos que hallamos en este corpus y, como ya ha tenido ocasión de indicar García-Page (2008: 91), su clasificación tiene validez como punto de arranque para el estudio de los fraseologismos, dado que supone una versión más depurada de la de Casares (1992) y de la de Zuluaga (1980). A dicha taxonomía se le efectuó una corrección que venía de parte de la fraseología alemana (B. Wotjak, 1992 y 1993) y se introdujeron las construcciones con verbo soporte (CVS) (Funktionsverbgefiuge). En cuanto al corpus de análisis, tenía un origen doble: por un lado, se tuvo en cuenta el material que le suministraron las cien encuestas directas que fueron realizadas por la autora del trabajo; pero, también se consideraron con mucho cuidado los distintos repertorios léxicos y fraseológicos que recogían unidades que se emplean en La Gomera. Su carácter diferencial fue validado mediante diccionarios generales y fraseológicos (por cuestiones de espacio, remitimos al tomo II de Tabares Plasencia (2006: 778-780) para el conocimiento y descripción de dichas obras y repertorios lexicográficos). En total se clasificaron y examinaron minuciosamente 386 unidades. De ellas, 376 son diferenciales, siendo que 10 locuciones estudiadas no pertenecen exclusivamente al habla de La Gomera, sino que se emplean en otros lugares del archipiélago canario, pero en esta isla canaria presentan una elevada frecuencia de uso. La estadística de las unidades analizadas, en su momento, atendiendo al tipo de unidades clasificadas es la siguiente:

\begin{tabular}{|l|c|c|c|c|c|}
\hline Tipo de unidad & Colocaciones & CVS & Locuciones & Enunciados fraseológicos & Todos los tipos \\
\hline $\mathrm{N}^{\circ}$ total & 109 & 13 & 208 & 56 & 386 \\
\hline
\end{tabular}


más confianza en la otra [profesora]". En aquel momento, estaba convencido de que se trataba de un caso de influencia catalana, ya que se sabe que las estructuras con fer 'hacer' del catalán influyeron el castellano de Cataluña, en el que abundan hoy en día (cf. Sinner, 2004) ${ }^{14}$.

La madre es extranjera y les habla a sus hijos en otra lengua, germánica, el padre, hijo de emigrantes canarios, es bilingüe y les habla en castellano y en catalán; los hijos van a un colegio catalán. Entonces, ¿̇cómo clasificar el caso del hacer confianza? ¿Es un canarismo, un catalanismo, un caso de convergencia? El fenómeno puede ser tanto una interferencia individual del catalán en el castellano de la hablante, puede ser un elemento generalizado en el español de Cataluña ya aprendido por ella (forma integrada) o puede ser un caso de convergencia entre la influencia canaria, el catalán y la tendencia del castellano de Cataluña. El hecho es que definitivamente forma parte del idiolecto de la niña. La chica en cuestión integra la misma comunidad de comunicación que Sinner (2004) estudia en su tesis doctoral, la de Cataluña. Se ve claramente el problema de la diferenciación del idiolecto de la niña y la adscripción de este fenómeno a un determinado grupo.

Otros ejemplos descritos en el trabajo mencionado sobre fraseología dialectal (en concreto, el uso diferencial de la isla de La Gomera) de Tabares (2006) considerados por otros hablantes insulares (o peninsulares) como erróneos o, cuando menos, extraños son dejar falta (algo a alguien), parar la atención (algo a alguien), echar (algo) al rojo y echar los cuernos (a alguien):

Dejar falta (algo a alguien) (Tabares, 2006 (2): 790) es una construcción verbonominal gomera que se usa en lugar de la general y normativa hacer falta, con el

14 El objetivo central de este estudio es el análisis de la frecuencia y aceptabilidad de determinados aspectos léxicos, morfosintácticos, pragmáticos y metalingüísticos del castellano de Cataluña para determinar si forman parte de las normas de uso regionales. La comparación de los valores de frecuencia y de aceptabilidad en el castellano de Cataluña y en otras variedades de la misma lengua sirven para comprobar la existencia de normas regionales del español de una de las regiones catalanohablantes españolas, del castellano de Cataluña. Para este fin, se realizaron entrevistas a 40 personas y de un total de 70 horas de duración en Barcelona (Cataluña) y Madrid (Castilla) sobre la aceptabilidad de elementos aparentemente divergentes en el español de Cataluña. Sobre la base de estas entrevistas, adicionalmente se llevaron a cabo análisis comparativos de la frecuencia de uso y diferentes pruebas complementarias sobre aspectos fraseológicos, morfológicos, semánticos y fonéticos. Los resultados de estos análisis contrastivos se compararon con las indicaciones referentes a los elementos estudiados en manuales de estilo, diccionarios monolingües y bilingües, manuales de dialectología, etc. De esta forma, no sólo pudo comprobarse la inclusión o no de los fenómenos en cuestión en dichas publicaciones, sino que también se pudo determinar hasta qué punto es posible que los resultados de las entrevistas y la actitud de los hablantes puedan relacionarse con el contenido de las obras de consulta analizadas. Si bien el estudio tenía como objetivo el análisis del castellano de Cataluña, muchos de los datos obtenidos permiten extrapolarlos a las demás regiones catalanohablantes de España (Valencia, islas Baleares, Aragón) y sirven de punto de comparación para estudios hispánicos contrastivos y trabajos de la índole que presentamos aquí. 
mismo significado de 'necesitar', 'ser necesario'. Un ejemplo sacado del corpus de grabaciones es: "Dejar falta, claro que lo uso yo siempre. Yo y todos aquí. Eso es cuando yo estoy en mi casa haciendo la comida y me doy cuenta de que me deja falta algo, que no tengo algo: ajos, un tomate, etc.”. Este ejemplo es igualmente muy interesante por el hecho de que el informante sea consciente del uso grupal o comunitario de la expresión.

Parar la atención (algo a alguien) (Tabares, 2006 (2): 797) apunta a la misma designación que la expresión llamar la atención, donde el verbo parar parece responder a un uso antiguo en el español, donde tenía la acepción de 'poner', acepción que tendió a quedarse anticuada a finales de la Edad Media. Según Corominas (1986: s.v. parar), frases como parar ojo 'poner atención' ya no se atestiguaban, prácticamente, a finales del Medievo. El ejemplo textual del corpus es el siguiente: “[...] Como a los guanches les gustaba adornar las puertitas con conchitas de lapas, a ella [la alemana] eso le paraba la atención”.

En el caso de echar (algo) al rojo y de echar los cuernos (a alguien) (Tabares, 2006 (2): 829), es interesante el empleo del verbo echar en lugar del más general poner. Sin poder argüir una influencia portuguesa -bastante importante en la isla-, lo cierto es que en el deitar portugués es muy alta la frecuencia de la acepción 'colocar'. Un ejemplo de la primera estructura es el siguiente extraído del corpus de Tabares (2006): "Bueno, ya hay varios chicos que los [a los anzuelos] tiemplan ellos, porque, cuando los destemplas, es como un arco, se quedan después flojos, se pueden partir. Lo cambas y, cuando te guste, pues lo tiemplas: lo echas al rojo, y cuando ya está rojo bastante, lo largas al aceite”.

Si bien hablantes de otras variedades dirían, sin vacilar, que se trata de lapsus o errores, el estudio empírico llevado a cabo por Tabares (2006) muestra que se trata de fraseologismos de uso "normal" y frecuente en una determinada comunidad de habla.

Otra muestra que podría aducirse en el contexto de la malinterpretación del estatus de elementos fraseológicos por desconocimiento de las variedades hispanas es el solapamiento de tecnicismos usados en diferentes variedades diatécnicas con otros ámbitos de uso. Sin embargo, por falta de espacio, no es posible desarrollar este aspecto en esta ocasión.

\section{CONCLUSIÓN}

Se ha visto claramente que hace falta indicar siempre a qué variedad se refieren los autores al pronunciarse acerca del estatus de una forma, en el contexto, de un fraseologismo. Obviamente, al hablar de una determinada variedad diatópica, sí se pueden usar "etiquetas" que vayan más allá de señalar que se trata de una variante, 
porque dejan claro para qué ámbito se supone que la etiqueta tiene validez. Lo que no resulta admisible es que se hable clases de variantes sin explicitar el nivel diasistemático del que se parte.

Por tanto, se considera que es necesario adoptar como punto de partida el concepto de variante para todos los fenómenos de variación fraseológica antes de subsumir estos en otras categorías como lapsus, error, formación ad hoc, etc.

Son necesarios, como se señaló supra, estudios empíricos cuantitativos basados en corpus amplios, dejando de lado la práctica habitual de basarse en las entradas de obras lexicográficas que casi siempre carecen de datación, procedencia exacta, frecuencias, etc., o se basan en estudios o datos no comparables entre sí (Sinner, 2016). Lo mismo, por cierto, cabría decir de muchos trabajos fraseológicos y paremiológicos que se limitan a dar listas con innumerables estructuras supuestamente "usadas" sin indicar ninguna de las informaciones anteriormente mencionadas: frecuencia de uso desglosando los géneros, variedades, emisores y el momento histórico en el que se usaban en el caso de los elementos caídos en desuso.

Antes de emitir ningún juicio acerca de la clase de variante que se da en el caso de un fraseologismo concreto, hace falta emplear análisis cuantitativos. Así se puede determinar la ubicación del elemento en cuestión en un continuo que vaya no sólo desde el extremo de las unidades que corresponden no a creatividad, sino a debilidades lingüísticas del emisor, errores verdaderos de producción, construcciones defectuosas, pasando por las formaciones ad hoc individuales sólo comprensibles por el contexto y la analogía (hecha por el receptor del enunciado) con formas o estructuras parecidas, etc., llegando al otro extremo de las construcciones que, sin duda alguna, constituyen fraseologismos usados por cualquier hablante/ emisor en cualquier momento, contexto, tipo de texto, etc.

Debe acabar la era de los estudios que no toman en consideración datos empíricos y que no justifican el uso de los fraseologismos o, fundamentalmente, sólo con el criterio basado en su registro en diferentes obras y repertorios lexicográficos, que, muchas veces, aparecen sin ningún tipo de marcación o con marcas poco claras o defectuosas.

\section{REFERENCIAS}

Alvarado Ortega, María Belén. (2008). Sobre el concepto de variación fraseológica. Estudios de Lingüistica: E.L.U.A., 22, 9-22.

Ammon, Ulrich. (1995). Die deutsche Sprache in Deutschland, Österreich und der Schweiz. Das Problem der nationalen Varietäten. Berlin, New York: De Gruyter. Androutsopoulos, Jannis. (1998). Deutsche Jugendsprache. Frankfurt am Main et al.: Lang.

Auer, Peter. (1989). Natürlichkeit und Stil. En Volker Hinnenkamp y Margret 
Selting (eds.) Stil und Stilisierung. Arbeiten zur Interpretativen Soziolinguistik. Tübingen: Niemeyer, 27-59.

Barz, Irmhild. (1986). Probleme der phraseologischen Modifikation. Deutsch als Fremdsprache, 23(6), 312-326.

Barz, Irmhild (1992): Phraseologie Varianten: Begriff und Probleme. En Csaba Földes (ed.) Deutsche Phraseologie in Sprachsystem und Sprachverwendung. Wien: Praesens, 25-47.

Bauman, Richard. (2000). Language, Identity, Performance. Pragmatics, 10, 1, 1-5. Baßler, Harald y Helmut Spiekermann. (2001). Dialekt und Standardsprache im DaF-Unterricht. Linguistik online, 9. ISSN 1615-3014. Disponible en www. linguistik-online.de/9_01/BasslerSpiekermann.html.

Benson, Morton (1985). Collocations and Idioms. En Robert Ilson (ed.) Dictionaries, Lexicography and Language Learning. Oxford: Pergamon, British Council, 61-68.

Berruto, Gaetano. (2004). Sprachvarietät - Sprache (Gesamtsprache, historische Sprache). En Ulrich Ammon, Norbert Dittmar y Klaus J. Mattheier (eds.) (2004-2005) Soziolinguistik. Ein internationales Handbuch zur Wissenschaft von Sprache und Gesellschaft. (2 ${ }^{\text {da }}$ edic. ampl., vol. 3.1). Berlin, New York: De Gruyter, 188-195.

Brumme, Jenny. (2008). La frase hecha, entre variabilidad e interferencia. En Carsten Sinner y Andreas Wesch (eds.) El castellano en las tierras de habla catalana. Frankfurt am Main, Madrid: Vervuert, Iberoamericana, 287-322.

Burger, Harald. (2000). La variación en fraseología. En Antonio Pamies Bertrán y Juan de Dios Luque Durán (eds.) Trabajos de lexicografía y fraseología contrastivas. Granada: Método, 105-118.

Burger, Harald (2003). Phraseologie: Eine Einführung am Beispiel des Deutschen. Berlin: Erich Schmidt Verlag.

Casares, Julio. (1992 [1950]). Introducción a la Lexicografía moderna. Madrid: CSIC.

Corpas Pastor, Gloria. (1996). Manual de fraseología española. Madrid: Gredos. Coseriu, Eugenio (1980): Historische Sprache und Dialekt. En Joachim Göschel, Pavle Ivić y Kurt Kehr (eds.) Dialekt und Dialektologie. Wiesbaden: Steiner, 106122.

Coseriu, Eugenio. (1988). Einführung in die Allgemeine Sprachwissenschaft. Tübingen: Francke.

Cutler, Cecilia A. (1999). Yorkville crossing: White teens, hip hop and African American English. Journal of Sociolinguistics, 3(4), 428-442.

Daher, Jamil. (1998). Gender in linguistic variation. The variable (q) in Damascus Arabic. En Elabbas Benmamoun, Mushira Eid y Niloofar Haeri (eds.) Perspectives on Arabic Linguistics XI. Amsterdam, Philadelphia: John Benjamins, 183-206. 
Dittmar, Norbert. (1997). Grundlagen der Soziolinguistik. Ein Arbeitsbuch mit Aufgaben. Tübingen: Niemeyer.

Dobrovol'skij, Dimitri. (1988). Phraseologie als Objekt der Universalienlinguistik. Leipzig: Enzyklopädie.

Dufter, Andreas y Elisabeth Stark. (2003). La variété des variétés: combien des dimensions pour la description? Quelques réflexions à partir du français. Romanistisches Jahrbuch, 53, 81-108.

Eckert, Penelope. (2012). Three Waves of Variation Study: The emergence of meaning in the study of variation. Annual Review of Anthropology, 41, 87-100.

Fischer, John L. (1958). Social influences on the choice of a linguistic variant. Word, $14,47-56$.

Fleischer, Wolfgang. (1982). Phraseologie der deutschen Gegenwartssprache. Leipzig: VEB Bibliographisches Institut.

García-Page, Mario. (1996). Sobre las variantes fraseológicas en español. Revista canadiense de estudios hispánicos, XX (3), 477-489.

García-Page, Mario. (1999). Variantes morfológicas y unidades fraseológicas. Paremia, 8, 225-230.

García-Page, Mario. (2008). Introducción a la fraseología española. Barcelona: Anthropos.

Gerstenberg, Annette. (2011). Generation und Sprachprofile im höheren Lebensalter. Frankfurt: Klostermann.

Giles, Howard y Peter Powesland. (1975). Speech style and social evaluation. New York, London: Academic Press.

Gómez Capuz, Juan. (2006). Así hablan nuestros famosos: una cala en el concepto de competencia comunicativa. Tonos. Revista electrónica de estudios filológicos, 11. ISSN 1577 6921. Disponible en https://www.um.es/tonosdigital/znum11/ estudios/9-famosos.htm.

Gross, Gaston. (1997). Du bon usage de la notion de locution. En Michel MartinsBaltar (ed.) La locution entre langue et usage. Lyon: ENS Edition Fontenay-Saint Cloud, 201-223.

Gross, Gaston. (2014). Mécanisme du figement dans les locutions finales. En Pedro Mogorrón Huerta y Salah Mejri (eds.) Fijación, Traducción, Variación y Desautomatización. Figement, Traduction, Variation et Défgement. Alacant: Universitat d'Alacant, 31-47.

Gumperz, John (1972). Sociolinguistics and Communication in Small Groups. En John B. Pride y Janet Holmes (eds.) Sociolinguistics. Selected Readings. Harmondsworth: Penguin, 203-224.

Guy, Gregory R. (1988). Language and Social Class. En Frederick J. Newmeyer (ed.) Linguistics: The Cambridge Survey. Language: the socio-cultural context. (vol. 4). Cambridge et al:: CUP, 37-63

Hutterer, Claus J. (1984). Der Dialekt als diatopische und diastratische Einheit. En 
Peter Wiesinger (ed.) Beiträge zur bairischen und ostfränkischen Dialektologie [...]. Göppingen: Kümmerle, 1-11.

Iturrioz Leza, José Luis y Stavros Skopeteas. (2000). Variation und Invarianz. En Geert Booij et al. (eds.) Morphologie. Morphology. [...]. An International Handbook on Inflection and Word-Formation. (vol. 1). Berlin, New York: De Gruyter, 234-247.

Koike, Kazumi. (2001). Variación fraseológica del español. Varilex, 9. Disponible en http://lingua.cc.sophia.ac.jp/varilex/index.php.

Koike, Kazumi. (2003). Las unidades fraseológicas del español: su distribución geográfica y sus variantes diatópicas. Epos, XIX, 47-65.

Kremnitz, Georg. (1995). Dimensionen und Dynamik kollektiver Identitäten [...]. En Sociolinguistica, 9, 67-87.

Kubczak, Hartmut. (1979). Was ist ein Soziolekt? Überlegungen zur Symptomfunktion sprachlicher Zeichen unter besonderer Berücksichtigung der diastratischen Funktion. Heidelberg: Winter.

Kubczak, Hartmut. (1987). Soziolekt. En Ulrich Ammon, Norbert Dittmar y Klaus J. Mattheier (eds.) Sociolinguistics. Soziolinguistik. An International Handbook of the Science of Language and Society. [...]. (vol. 1). Berlin: De Gruyter, 268-273.

Larousse (2001). Gran Diccionario de Frases Hechas. Barcelona: Larousse.

Löffler, Heinrich. (2005). Germanistische Soziolinguistik. (3a edic.). Berlin: Schmidt. Martí Sánchez, Manuel. (2014). Motivación y arbitrariedad en la desautomatización fraseológica (sobre sus implicaciones didácticas). En Pedro Mogorrón Huerta y Salah Mejri (eds.) Fijación, Traducción, Variación y Desautomatización. Figement, Traduction, Variation et Défigement. Alacant: Universitat d'Alacant, 89-115.

Mejri, Salah. (2005). Figement absolu ou relatif: la notion de degré de figement. Linx, 53, 183-196.

Mejri, Salah y Arianne Desporte. (2010). Opacité et idiomaticité des expressions figées: deux repères en traduction. En Pedro Mogorrón Huerta y Salah Mejri (eds.) Opacidad, idiomaticidad, traducción. Opacité, idiomaticité, traduction, Alacant: Universitat d'Alacant, 229-235.

Mena Martínez, Florentina (2003). En torno al concepto de desautomatización: aspectos básicos. Tonos Digital: Revista Electrónica de Estudios Filológicos, 5. Disponible en: https://digitum.um.es/xmlui/bitstream/10201/50794/1/En\%20 torno\%20al\%20concepto.pdf.

Mogorrón Huerta, Pedro. (2010a). Analyse du figement et de ses possibles variations dans les constructions verbales espagnoles. Linguisticae Investigationes, XXXIII, 86-151.

Mogorrón Huerta, Pedro. (2010b). Estudio contrastivo lingüístico y semántico de las construcciones verbales fijas diatópicas mexicanas/españolas. En Cesáreo Calvo Rigual, Brigitte Lépinette Lepers y Jean Claude Anscombre (coords.) Le- 
xicografía en el ámbito hispánico. València: Universitat de València, 179-198. Mogorrón Huerta. Pedro (2010c). Estudio contrastivo lingüístico y semántico de las construcciones verbales fijas diatópicas mexicanas/españolas. Quaderns de Filologia. Estudis linguistics, XV, 179-198.

Mogorrón Huerta, Pedro. (2014a). Las expresiones fijas diatópicas argentinas y mexicanas. En María Isabel González Rey (coord.) Didáctica y traducción de las unidades fraseológicas. Santiago de Compostela: Universidade de Santiago de Compostela, 77-94.

Mogorron Huerta, Pedro. (2014b). ¡Se usan las mismas expresiones fijas en España y en Hispanoamérica! En Pedro Mogorrón Huerta y Salah Mejri (eds.) Fijación, Traducción, Variación y Desautomatización. Figement, Traduction, Variation et Défgement. Alacant: Universitat d'Alacant, 49-61.

Möhn, Dieter. (1998). Fachsprachen und Gruppensprachen. En Lothar Hoffmann et al. (eds.) Fachsprachen / Languages for Special Purposes. [...] An International Handbook of Special-Language and Terminology Research. (2 vol.). Berlin, New York: De Gruyter, 169-180.

Montoro del Arco, Esteban T. (2004). La variación fraseológica y el diccionario. En Paz Battaner y Janet DeCesaris (eds.) De Lexicografia. Barcelona: Institut Universitari de Lingüística Aplicada, 591-604.

Montoro del Arco, Esteban T. (2005). Hacia una sistematización de la variabilidad fraseológica. En María Ángeles Pastor Milán (ed.) Estudios lingüísticos en recuerdo del profesor Juan Martinez Marin. Granada: Universidad de Granada, 125-152.

Montoro del Arco, Esteban T. (2006). Teoría fraseológica de las locuciones particulares. Las locuciones prepositivas, conjuntivas y marcadoras en español. Frankfurt am Main: Peter Lang.

Nabrings, Kirsten. (1981). Sprachliche Varietäten. Tübingen: Narr.

Oksaar, Els. (1987). Idiolekt. En Ulrich Ammon, Norbert Dittmar y Klaus J. Mattheier (eds.) Sociolinguistics. Soziolinguistik. An International Handbook of the Science of Language and Society. Ein Internationales Handbuch zur Wissenschaft von Sprache und Gesellschaft. (vol. 1). Berlin: De Gruyter, 293-297.

Oksaar, Els. (2000). Idiolekt als Grundlage der variationsorientierten Linguistik. Sociolinguistica, 14, 37-42.

Penadés Martínez, Inmaculada. (2014). Variación no marcada / variación marcada en las locuciones: implicaciones para la traducción. En Pedro Mogorrón Huerta y Salah Mejri (eds.) Fijación, Traducción, Variación y Desautomatización. Figement, Traduction, Variation et Défigement. Alacant: Universitat d'Alacant, 63-87.

Real Academia Española. (2014). Diccionario de la lengua española. Disponible en http://dle.rae.es/index.html.

Ruiz Gurillo, Leonor. (1997). Aspectos de fraseología teórica española.València: Universitat de València.

Salvador, Vicent. (2000). Idiomaticitat i discurs prefabricat. En Vicent Salvador y 
Adolf Piquer (eds.) El discurs prefabricat. Estudis de fraseologia teòrica i aplicada. Castelló de la Plana: Universitat Jaume I, 19-32.

Sinner, Carsten. (2002). The construction of identity and group boundaries in Catalan Spanish. En Anna Duszak (ed.) Us and Others: social identities across languages, discourses and cultures. Amsterdam y Philadelphia: Benjamins, 159-185.

Sinner, Carsten. (2004). El castellano de Cataluña. Estudio empirico de aspectos léxicos, morfosintácticos, pragmáticos y metalingüisticos. Tübingen: Niemeyer.

Sinner, Carsten. (2014). Einführung in die Varietätenlinguistik. Tübingen: Narr.

Sinner, Carsten. (2016). Fehlende Berücksichtigung diasystematischer Dimensionen als Prozessfehler. En Carolin Patzelt y Elton Prifti (eds.) Diachrone Varietätenlinguistik. Berlin: De Gruyter.

Steger, Hugo. (1988). Erscheinungsformen der deutschen Sprache: 'Alltagssprache' - 'Fachsprache' - 'Standardsprache' - 'Dialekt' und andere Gliederungstermini. En Deutsche Sprache, 16, 289-319.

Steinig, Wolfgang. (1976). Soziolekt und soziale Rolle. Düsseldorf: Schwann.

Tabares Plasencia, Encarnación. (2006). Vocabulario tradicional de La Gomera. (2 vols). Islas Canarias: Academia Canaria de la Lengua.

Tabares Plasencia, Encarnación. (2012). Analyse und Abgrenzung rechtssprachlicher phraseologischer Einheiten im Spanischen und Deutschen und ihre Bedeutung für die Übersetzung. Lebende Sprachen, 57(2), 314-328.

White, Edmund. (2010). City Boy. My Life in New York During the 1960s and 1970s. London: Bloomsbury.

Wotjak, Barbara. (1992). Verbale Phraseolexeme in System und Text. Tübingen: Max Niemeyer.

Wotjak, Barbara. (1993). Sage und schreibe. Deutsche Phraseologismen in Theorie und Praxis. Leipzig, Berlin, München: Langescheidt.

Zuluaga, Alberto. (1980). Introducción al estudio de las expresiones fijas. Tübingen: Max Hueber.

Zuluaga, Alberto. (1998). Sobre fraseoloxismos e fenómenos colindantes. En Xosé Ferro Ruibal (coord. y ed.) I Coloquio Galego de Fraseoloxía, Santiago de Compostela, Xunta de Galicia, 15-30. 